put her foot to the ground, and even step out, bearing the weight of the body. She has long ago been able to move without the aid of a stick, has been out of doors, and perfectly competent to take exercise on foot when the weather permits, no deformity ex isting in the parts.

This case is placed before the surgical world, particularly the junior portion, as a reason for not being dispirited in prognosticating osseous union in subjects far advanced in life, as, in the present instance, at first, it was pronounced to be not at all likely that any other than cartilaginous union would take place, and that therefore Mrs. F. would terminate her days as a cripple, from want of power in the system to unite the fractured bone. It is hoped its relation may call forth reports of any similar instances occurring in the practice of some of your numerous readers and correspondents. I am, Sir, your obedient servant,

W. F. Henderson, M.D., Surgeon.

Clapham-rise, Jan. 5, 1843.

\section{VAGINAL DISCHARGE}

IN

CHILOREN.

\section{IRON IN GLEET, ABSCESS, AND} DEBILITY.

To the Editor.-Sir: In answer to the inquiry of "C." (LANCET, Dec. 24), relative to the treatment of vaginal discharge in children, I beg to inform him that I have lately seen a case which readily yielded to calomel, rhubarb, and cinnamon, given every morning, employing, as au external application, a lotion composed of spirits and limewater, and which was afterwards changed for one made with the decoction of oak-bark and the tincture of galls.

I observe that Dr. Allnatt (page 504), in noticing this subject, advises the creosote injection for the cure of gleets, and as these cases are of some moment, perbaps I may be allowed to trouble you with the following:-About six months since, J. H., retat. 25, presenting a pale, pasty aspect, applied to me in consequence of suffering from a urethral discharge, the effect, he believed, of a gonorrhoea which he had contracted two years previously. He had been under the care of three London surgeons of some note; the ordinary injections had been used, and both the disulphate of quina and the steel mixture had been administered, without his experiencing much relief. The discharge had persisted for nearly two year's, was of a yellowish-white colour, and did not exceed more than a teaspoonful during the day. He was depressed in spirits, and "would give anything if he he could only get rid of it," as he was desirous of being married. I ordered him$\mathrm{R}$ Disulphate of quina, one scruple; citric acid, eighteen grains; best orange wine, twenty-six ounces. - Make a mixture, of which three tablespoonfuls are to be taken three times a day, with aloetic myrrh pill every other morning. This treatment was continued for a fortnight, and a cold silver catheter was passed every alternate day, but it appeared to exert no decided influence over his disease. I then directed him to take six drops of Mr. Tyson's "liq. ferri oxysulphatis," twice a-day, in a wineglassful of water, and prescribed the follow. ing injection, to be employed thrice daily :$\mathrm{B}$ Iodide of iron, four grains ; distilled water, eight ounces. The injection produced some pain, and at first appeared to increase the discharge, but in five days it had entirely ceased, and $\bar{l}$ believe has never returned. The internal exhibition of the iron was persevered in for a month, when, owing to his being attacked with catarrh, it was omitted.

A few weeks agro a man was admitted into the Casualty Hospital of this town who was afflicted with an old sinuous abscess, which was situated on the posterior region of the right thigh. It was laid open, pledgets of lint, dipped in a solution of iodide of iron, were inserted into the wound, and a poultice was applied. Free suppuration was speedily induced, its cavity became completely obliterated, and he was dismissed cured. In this instance the iodide of iron was also given internally. Might not a weak solution of this preparation be tried as an injection in obstinate leucorrhoea?

With regard to the "liq. ferri oxysul. phatis," I may mention that $I$ have taken it myself, combined with the infusion of calumba and wine of aloes, for the relief of debility, \&c., caused by tropical dysentery, and $I$ fancy that $I$ have derived benefit from it. Should it not be prepared with a less quantity of nitric acid than that ordered by Mr. Tyson? I am, Sir, yours obediently,

T. C. LEwIs.

Wolverhampton, January 10, 1843.

Oestinate Constipation. - In a recent debate, Dr. Chowne mentioned an inslance in which habitual constipation in an hysterical girl aged fourteen years, gave way before the internal use of croton oil, and injections of the same remedy. She had frequently gone a week without a motion; sometimes a fortnight, and, on one occasion, a month. In the same debate Dr. Reid stated that he had found, in a case of obstinate constipation in a young bysterical girl, that the most effectual way of producing an action of the bowels was to apply seven or eight leeches to the abdomen. This plan was found to be successful when all other means had been of no avail. Mr. Suow advocated the use of enemata of warm water in cases of obstinate constipation, the continual use of violent purgatives being liable to be followed by inflammatory mischief. 